\title{
Medical Technology and Organizational Context: Deep Brain Stimulation for Parkinson Patients
}

\author{
Elsa G* \\ Researcher in Social and Human Sciences \\ *Corresponding author: Elsa Gisquet, Researcher in Social and Human Sciences, \\ Institute National du Cancer, 52, avenue Andre-Morizet, 92100 Boulogne-Billancourt, \\ France, Tel: +33609535699; Email: elsa.gisquet@gmail.com
}

\section{Case Report}

Volume 1 Issue 2

Received Date: July 24, 2017

Published Date: October 27, 2017

DOI: $10.23880 /$ phoa-16000113

\section{Abstract}

Despite the long history of DBS, it's under lying objectives are still not clear. What can really be expected from this technique? What are its benefits for the patients? This study explores the way in which a medical technique is implemented in interaction with the local environment. Based on several months of fieldwork, the analysis shows how organizations shape the translation of medical techniques, influencing the way physicians use technologies but also influencing desirability and acceptability for patients. Four local organizational dynamics which affect the use of a medical technology have been identified: the sense-making of the medical technology, the involvement in the new technology, the allocation of this resource to patients and the setting of parameters. The results highlight that those organizational settings can have real effects on the patient's experience. This result is significant for the design of public health policies.

Keywords: Medical innovations; Local orders; Biotechnologies; Medical practices; Doctor-patient relationships; Parkinson

\section{Introduction}

Deep brain stimulation (DBS) is a surgery procedure that sends electrical impulses, through implanted electrodes, to specific parts of the brain (brain nucleus) for the treatment of movement and affective disorders, such as Parkinson's disease. Despite the long history of DBS, it's under lying objectives are still not clear. What can really be expected from this technique? What are its benefits for the patients?

A significant contribution of sociology to our understanding of medical technology is to reveal that use of medical technology is fundamentally a social process. A particularly promising direction has been to examine the socio technical influences on whether and how technologies enter into use $[1,2]$.

This also resonates with a classical premise in STS: the idea that the different meanings, promissory visions and utility values are assigned to technologies according to the context of use. Social issues affect the institution and use of technologies and, in turn, technology modifies certain social aspects [3-5] showing that institution and implementation depend on the production and challenging of evidence in complex interactions between technology and local constraints [6-8]. The contextual dynamics of technology must be taking account to explore actors' interactions with technology [9]. 
Despite these insights there is a lack of understanding of the relationship between organization and medical device. No work has yet considered the way in which the use of a medical technology is constructed in interaction with the environment in which it is integrated [10]. Until recently, medical technologies have received less attention than pharmaceuticals [1] and have been less taken into account at the local level. Through the case of deep brain stimulation (DBS) for Parkision patients, this study underlines the importance of an organizational analysis for understanding the limits of public health policies because of local arrangements.

Our study was designed to fill this gap and aimed to identify of how local organizational factors influence the use of medical technology. Bases on several months of field work; the analysis shows how organizations shape the use of medical technology, influencing the way physicians use technologies but also influencing desirability and acceptability for patients. At least they affect the experiences of the patients receiving the DBS, and that of their loved ones. Data, taken from interviews and case studies, suggest that staff members, because of the differing organizational context of work, may arrive at opposing situations of use and experience.

The first part of this article will present the case description of this study. In the second part, the four local organizational dynamics affecting use of medical technology will be presented. At the end, the consequences of use of medical technology on the patient's experience will be analyzed.

\section{Case description}

Parkinson's disease is the second cause of motor disability in adults, after strokes. The disease affects $2 \%$ of adults over 60 years, but is also found in young adults. It affects family life, but also professional and social. The period during which the drugs are completely effective only extends about 5 to 10 years $[11,12]$.

DBS is now a standard treatment for Parkinson's disease. If healing is not possible, neurostimulation improves motor disorders associated with Parkinson's disease (akinésies, dyskinesias) and its drug treatment $[13,14]$. Rating scales of neurostimulation therapy emphasize mainly motor and cognitive skills of Parkinson's patients. But side effects may also be harmful, such as psychiatric troubles. The patient, as if "overstimulated" sometimes oscillates between a phase of excitement and uninhibited conduct which can range from an addiction for gambling to sexual obsession, to suicide in some cases [15]. In addition to these problems, other psychiatric disorders have been reported [16] manifested by changes in mood or irritability or the apathy [17].

France attempted to regulate the use of neurostimulation through a consensus conference by a list of criteria: be age over 70 years, duration of disease progression over 5 years, illness severity based on a motor score, a good general state of health to support the operation and no psychiatric disorder. Finally, only 10\% of Parkinson's patients may benefit from DBS.

Patient candidates must pass a series of tests. Then patients are operated on to implant two electrodes into the sub thalamic nucleus whose size is comparable to a grain of rice. A week after surgery, the patient is operated again to fit a pacemaker (battery) under the clavicle. Then, initial setting can begin. The neurologist put a small box connected with a wire on the patient's clavicle. After changing the electric intensity, the doctor asks his or her patient to walk down the corridor to test the effects.

\section{Materials and Methods}

The field work included two neurology units practicing DBS. Unit A is located in the Paris area and unit B in a less urban area, $100 \mathrm{~km}$ away. The observation period (6 months for unit A and 4 months for unit B) was used for a better understanding of the main concerns and attentions of neurologists, patient complaints, and how they were received and treated by their doctor. The main steps of DBS have been observed: consultation, selection, operation, setting.

Observations have been complemented by ten interviews with physicians (mainly neurologists) in each unit to understand their relationship with DBS. Interviews were also conducted with the first 10 patients presenting at each site for a consultation, to understand their experiences with DBS.

\section{Results}

\section{Organizational settings affect the appropriation of technological innovation}

Sense Making : The medical and scientific issues are then elaborated with the sense-making which is defined by each medical organization [18]. People engage with new medical technology in search of answers to the question "what for? What can we expect?"People organize to make sense of equivocal inputs and enact this sense back into the world, making that world more orderly $[19,20]$. 
Sense-making is enacted according to each organizational context. In Unit A physicians believe DBS allow patients to "be reborn": "Suddenly, you go from death, disability, chronic illness to a person who is very euphoric because they want to eat out, to travel, to resume being anything you want"(neurologist, unit A).

The representation of the future quality of life after treatment is seen as almost equivalent to the life before the disease even if it still recognizes "that the cure is not possible."

Physicians in unit B on the other hand mainly perceive DBS through neurostimulation equivalence with drug treatments (when they are most effective). The neurologists' expectations regarding the technique are relatively low. DBS is considered as a possible treatment, among others, in advanced

Parkinson's Disease: "The problem with neurostimulation is that there are new side effects. The confusion syndrome, for example. The patients sometimes lose their spatio-temporal references; they speak incoherently when it was going well before [the treatment]. That is very difficult for us, for the whole team and for the family. It's something that one experiences as very hard. That remains a big failure for us and for the patient and a trial for the family." (Neurologist)

For unit $\mathrm{B}$, the advantage of this technology lies in the elimination of side effects from drug treatments. It is essential to preserve quality of life of patients despite motor improvement:

The organization is both a fixed structure and emerging patterns [21]. Organizing consists of reducing differences among actors through institutionalized cognitive representations [19]. The results of this study highlights that the sense-making varies according to organizational contexts [18] and more specifically based on the involvement in the medical technology.

\section{Involvement in the Medical Technology}

Unite A was one of the first services in France to try the DBS, just after its discovery. Unit A is a small team dedicated to research (drug testing and experimental techniques) team. This team involved very early in the implementation of this medical technology. Despite a high turnover related to young researchers often from all over Europe, the team members are welded by a common ambition to be known on the international scientific stage in neurology. DBS is a very promising research topic for this unit because it can be tested with other diseases (such as anorexia or depression). In addition, new treatment provides information on the Parkinson's disease and more broadly on the brain [22]. It appears that a medical team has higher expectation in DBS when their stakes in the development of this medical technology are high.

Taking place within a regional university hospital, unit B completed its first neurostimulation in 1997. This is a "classical" neurology unit specialized in Parkinson's disease. DBS contributed to the attractiveness of the neurology unit, but it has never been used to be recognized on the international scientific scene. In this Unit, there are fewer expectations for DBS.

It has already been highlighted that organization context is associated with the adoption and implementation of the innovation to its diffusion at the population level [23]. In this case, the higher the stakes, the more the medical team uses in the medical technology, and participates in its improvement, development and translation to the patients.

\section{Resource Allocation}

DBS modifies the configuration of medical work and creates a realignment of medical activities [24]. This new technology can be considered as a scare resource [9] because it can only benefit a few patients for medical and economic reasons. Thus, this new technology has expanded the content and meaning of Parkinson's disease diagnosis by adding a medical judgment: who should benefit from this treatment?

In unit $\mathrm{A}$, the patient complies with a strictly medical definition of the situation. Patient motivation is not evaluated. The medical team checks that clinical test results match with criteria required for such operation. However, exceptions are sometimes possible, according to the team's expression of "compassionate indication." The patient may beat too late a stage of the disease to responds strictly to all the inclusion criteria. But unit A is so convinced of the benefits of this technique that it sometimes ignores certain restrictive criteria to give a chance to its patients, especially for young patients in severe pain. At the same time, these exception sallow's to explore others development of the DBS beyond the medical guidelines.

In unit $\mathrm{B}$, in addition to the medical criteria guidelines, the patient's motivation is crucial. It is checked systematically and repeatedly that the patient is 
motivated to use DBS, even if he or she meets the clinical criteria for inclusion. Since DBS is considered as one treatment among many, involving major surgery and possible side effects, it is verified that the patient is ready to overcome this ordeal. Ensuring the patient's motivation is also a way to be sure of patient compliance throughout the pre and post-operative routine which can be very long and challenging:

"For example, if a patient says "it annoys me to take 3 weeks of sick leave," we don't operate. It means that the patient is not ready to accept such a change "(neurosurgeon, Unit B).

In Unit B patients must comply with the inclusion criteria and might be refused due to a lack of motivation.

Finally, the criteria for selecting candidates are the result of involvement in the construction of the medical technology and the sense-making shared by each medical unit. The selection process has a different functionality according to unit-specific issues.

\section{Setting Parameters}

The "right" setting for the DBS parameters has a subjective dimension that may vary locally. Following the operation, neurologists are willing to receive their patient many times, even in outside consultation, to reach an optimum adjustment. However, this availability, this "perpetual search of better" is essentially limited in terms of motor abilities in Unit A. The issue is that the patient can move as closely as possible to before the illness. Other types of complaints, such as personality disorders, are rejected by the medical team.

The Unit B medical team has a more holistic view of their patients, including the social consequences of the operation. Some hospitalizations are admitted because of relationship issues or social isolation. They take responsibility for the consequences of the operation, including on the social side of patient's life.

The determination of a "good" setting results from social contingencies. The focus may be on an optimal result in terms of motor skills or social support and relationships of the patient in this new phase of the disease. The subjective definition of what is "acceptable" for the patient varies according to the locally defined sense-making.

\section{The Experience of Patients}

After having shown the way in which organizational context can affect the usage of a medical innovation, we will now consider the consequences of this for the patients considering that conceptions of patients and their roles may vary according to local contexts [25].

Team unit $A$ ensures that patients respond well to the rapeutic indications. There is no time dedicated to the explanation of the treatment and its potential risks. Information is transmitted through usual and regular consultations. Patients treated by unit A complain about not having been sufficiently informed of the limits of neurostimulation and regret the lack of supervision:

"After surgery, it is serious, you are lost in the wilderness. If I was told that my husband might have personality disorders, I might have helped him better, because then I could not understand anything." (Wife of a stimulated patient).

The incomplete information given in advance did not allow patients to anticipate the consequences of the operation. Patients and their families can't adjust their expectations to the DBS devices and its limits. However, patients feel great gratitude to the neurologists, probably due to the close relationship established with them.

In the unit B, at the end of the selection week, a consultation is specially contracted to officially inform patients about the decision to submit the risks and consequences of operation, and to ensure the consent and motivation of the patients. After the operation, the doctors again impress on their patients the limits of treatment in order to identify their needs and encourage them to accept their new capacities. Patients feel well informed about the risks of the operation, which helps to cope with the new situation: "I wanted to be like before. But I was warned that it would not be perfect, but I'd better. So I was warned ".

Patients are very satisfied with the support they received. They are not surprised when the results are not up to what they expected. They also feel that the medical team is available to answer even non-medical problems and find solutions.

In summary, DBS creates a specific form of biographical rupture [26-28]. A time of adaptation to these hybrid 
bodies [3] is necessary. In particular, the patients should learn to use their new capacities and accept the limits of the treatment [28].

Autonomy should be seen through the prism of local configurations. The hybrid bodies are the object of negotiations with physicians and at the end, it is the notion of autonomy itself which is questioned [29].If the patients show a greater autonomy in their bodies and their movements, the ties with the hospital are marked by a stronger dependence after the DBS. In this regard it is interesting to note that the dependent relationship is characterized differently in different hospitals. In unit A, dependence takes root from the availability of the doctors to respond to the needs of their patients in terms of their mobility. In unit B it is established in the presumed choice of the team to support their patients even in the social and familial realms. The autonomy of the patients as a subject can also vary according to the contexts of the action, according to the degree of information transmitted to the patient in order to get their consent for the operation.

The way, in which the patients are informed and prepared for the operation, listened to and accompanied during the follow-up, relates closely to the medical practices which are constructed and elaborated locally.

\section{Discussion}

If STS often refers to the importance of the local order, they have yet not clarified the factors by which practices vary locally. Our study contributes to identifying the key relationships between organizational structure and the use of a medical technology. Four organizational aspects could explain the dynamic of local constructions of technical innovation and their effects on the patient experience. 1/ The sense making about this medical device is particularly affected by the stake in it shared by local contexts, according to the value of such a new treatment. The sense making process generalized and institutionalized specific meanings and rules of DBS [21], p. 570). 2/ The more researchers are involved in the development and implementation of technical devices, the more they are interested in their technical education and the less on their social consequences [30]. 3/ The criteria for attribution of this medical technology and the 4/ parameters of the DBS are constructed according to the expectations and the sense making which are constructed locally.

Consequently, the way in which patients are informed and prepared for the operation, listened to and accompanied during the follow-up, depends closely on the sense making and more broadly the dynamic of medical practices which are constructed and elaborated locally.

Local arrangements show a consistency not only driven by professional concerns [31] or by strategic behavior to maintain a degree of independence [32] but constructed in line with local agreements. Each local organization is a self-sustaining system with in which it is essential to justify the use of a technology, allocate access rights for the patients, and legitimize new professional practices and types of interactions with patients. Taking into account these different organizational characteristics allows us to make explicit the variability of medical practices and the gaps that can exist between the recommendations of the authorities and medical practice.

\section{References}

1. Ulucanlar S, Faulkner A, Peirce S, Elwyn G (2013) Technology identity: The role of sociotechnical representations in the adoption of medical devices. Soc Sci Med 98: 95-105.

2. Gardner J (2017) Understanding Innovation and the Problem of Technology Adoption. Rethinking the Clinical Gaze 27-56.

3. Akrich M, Dodier N (1995) "Techniques et Culture. Présentation " Techniques \& Culture 25: 1-11.

4. Timmermans S, Berg M (2003) The practice of medical technology. Sociol Health Illn 25: 97-114.

5. Cambrosio A, Keating P, Schlich T, Weisz G (2006) Regulatory objectivity and the generation and management of evidence in medicine. Soc Sci Med 63(1): 189-199.

6. Hyysalo S (2006) Representations of use and practice-bound imaginaries in automating the safety of the elderly. Social Studies of Science 36(4): 599626.

7. Obstfelder A, Engeseth KH, Wynn R (2007) Characteristics of successfully implemented telemedical applications. Implement Sci 2(25): 1-11.

8. Bijker WE (2010) "How is technology made? That is the question!" Cambridge Journal of Economics 34(1): 63-76.

9. Abrishami P, Boer A, Horstman K (2015) How can we assess the value of complex medical innovations in 
practice? Expert Rev Pharmacoecon Outcomes Res 15(3): 369-371.

10. Jeffries M, Phipps D, Rachel LH, Anthony A, Sarah R, et al. (2017) Understanding the implementation and adoption of an information technology intervention to support medicine optimisation in primary care: qualitative study using strong structuration theory. BMJ open7(5): e014810.

11. Mardsen C, Parkes J (1977) Success and problems of long-term levodopa therapy in Parkinson's disease. Lancet 1(8007): 345-349.

12. Bonnet AM, Loria Y, Saint Hilaire MH, Lhermitte F, Agid Y (1987) Does long-term aggravation of Parkinson's disease result from nondopaminergic lesions? Neurology 37(9): 1539-1542.

13. Benabid A, Benazzouz A, Hoffmann D, Limousin P, Krack P, et al. (1998) "Long-term electrical inhibition of deep brain targets in movement disorders." Mov Disord 13(3): 119-125.

14. Houeto JL, Damier P, Bejjani PB, Staedler C, Bonnet AM (2000) Subthalamic Stimulation in Parkinson Disease: a multidisciplinary approach Arch Neurol 57(4): 461-465.

15. Volkmann J, Daniels C, Witt K (2010) Neuropsychiatric effects of subthalamic neurostimulation in Parkinson disease. Nat Rev Neurol 6(9): 487-498.

16. Kosel M, Sturm V, Frick C, Lenartz D, Zeidler G, et al. (2007) Mood improvement after deep brain stimulation of the internal globus pallidus for tardive dyskinesia in a patient suffering from major depression. J Psychatri Res 41(9): 801-803.

17. Beijani BP, Houeto JL, Hariz M, Yelnik J, Mesnage V, et al. (2002) "Agressive Behavior induced by intraoperative stimulation in the triangle of Sano." Neurology 59(9): 1425-1427.

18. Peckham S, Exworthy M, Sheaff R, Halliday J, Byng R, et al. (2017) Bridging the discursive gap between lay and medical discourse in care coordination. Sociol Health Illn.

19. Weick KE (1979) "Cognitive processes in organizations." Research in organizational behavior 1(1): 41-74.
20. Weick KE (1993) Sensemaking in organizations: Small structures with large consequences. Social psychology in organizations: Advances in theory and research 10-37.

21. Tsoukas H, Chia R (2002) On organizational becoming: Rethinking organizational change. Organization Science 13(5): 567-582.

22. Bonetti E (2007) L'impuissance et son traitement. Annales. Histoire, Sciences sociales, Éditions de l'EHESS.

23. Compagni A, Mele V, Davide Ravasi (2015) How early implementations influence later adoptions of innovation: Social positioning and skill reproduction in the diffusion of robotic surgery. Academy of Management Journal 58(1): 242-278.

24. Bourret P, Keating P, Cambrosio A (2011) "Regulating diagnosis in post-genomic medicine: Re-aligning clinical judgment ?" Soc Sci Med 73(6): 816-824.

25. McDermott AM and Pedersen AR (2016) Conceptions of patients and their roles in healthcare: Insights from everyday practice and service improvement." J health organ Manag 30(2): 194-206.

26. Bury M (1982) Chronic Illness as biographical disruption. Sociol Health Illn 4(2): 167-182.

27. Charmaz K (1983) Loss of self: A fundamental Form of Suffering of the Chronically Ill. Sociology of Health \& Illness 5(2): 168-195.

28. Gisquet E (2008) Cerebral implants and Parkinson's disease: A unique form of biographical disruption? Soc Sci Med 67(11): 1847-1851.

29. Haraway DJ (1991) Simians, Cyborgs and Women: The Reinvention of Nature.

30. Collins A, Kendall G, Mike Michael (1998) Resisting a diagnostic technique: the case of reflex anal dilatation. Sociology of Health \& Illness 20(1): 1-28.

31. Castel P, Merle I (2002) When standards become a resource for doctors: The case of oncology. Sociologie du travail 44(3): 337-355.

32. Ogien A (2000) Medicine, health and management. Occupations and health institutions in relation to the organization of work. Pp : 133-148. 